\title{
Robert Nelson
}

\author{
Monash University
}

\section{Doctoralness in the Balance:The Agonies of Scholarly Writing in Studio Research Degrees}

According to a canon that developed unchallenged for a very long time, academic research exists in fields of knowing and proof. It is identified most memorably and with the greatest severity in the physical sciences, which establish facts on the basis of observation, very often extending to empirical experiment, where circumstances are carefully created and controlled, and tests are reliably designed around an unsolved question. This method is reflected in the social sciences, which describe, quantify and model social phenomena - economic or behavioural - without experiment but with the same code of measurable rigour. The humanities, which are by and large nonquantitative and definitely present a greater kinship with the creative arts in their cultural subject matter and often in the ideological spirit of their contentions, also cleave closely to the motif of knowing and proof.

Disciplines like philosophy, history and languages interpret and argue with the support of sources; a thesis in the field is held to be defensible when its conclusions and methods withstand the contrary argument.

What then is the counterpart in the creative arts? The primary motif is making; and then there is normally further supplementary material, whence a further question of 'saying what?' arises. Somehow the additional saying (the verbal accompaniment to new creative work) seems auxiliary and in some post-structural work, for example, may even present certain embarrassments. Some artists would challenge the logocentric suppositions of the other disciplines. It seems an unhappy compromise to capitulate to the terms of linear argument in language when the whole project seems dedicated to avoiding those premises. In the creative arts, the 'fields of knowing and proof' are not always as obvious as the sensual transport of the work; and it is even difficult to identify that conclusions have been arrived at. The material established through the research is often fugitive and resists a satisfactory definition. We all agree that creative work is research, for its self-evidently innovative character and generation of new concepts, forms and emotional engagement; but its disciplinary criteria suffer vague parameters.

In university life, there seems to be a seamless tradition without us, an integrity of knowing what to ask, knowing what to do and knowing what to say that perhaps reflects the mutual intimacy of reading, gleaning, judging, assaying, proving and arguing. The other disciplines have a 'natural' rapport between the various stages of searching, testing and reflecting; they are based on a designed closeness of stab and lab. You read, scrutinize, learn, find fault, make notes and gather sources critically alongside your own gestating ideas. You identify the unknown or the unspoken, perhaps even certain things unfelt by others. In this exploration, writing logically completes the journey. There is no disjunction between the 'work' and the writing, even though we know 
that many researchers in some technical areas are chronically dysfunctional writers.

The creative arts could almost be seen delivering the opposite framework. In research degrees, candidates complete a schismatic project that comprises (a) doing and (b) writing about doing. The two are ideally linked but nothing guarantees the link and much discourages it. The creative element is normally central and has to be granted some dignity as an autonomous entity, not necessarily connected with writing. Among some artists, the work may be perfused with dependence on an exegetical text, like a catalogue essay; but this synergy of word and image cannot be generalized. However much influenced by writing, the creative work has to be allowed an inalienable integrity.

Further, the key body of investigative work (the creative output) has fierce attachments or investments of an emotional or ideological kind and therefore contests any lure of objectivity that the other disciplines may project. When we write, we somewhat shamelessly undertake a thinly veiled labour of valorizing what has been achieved in the creative work. No one really wants to challenge the work, for this would perversely invite the examiners' disapproval; besides, as artists we are hardwired to construct arguments in our favour. Challenging the data with impartial tests is inconceivable in our field. More often than not, we create a rhetorical text to convince the reader that the conceits of the creative work are topical and necessary.

The problem is not the writing itself - the fact that we use writing when our medium is paint or pixels - as if writing is an alien medium in which nothing properly translates. The problem is equally encountered in creative writing projects, where the candidate is an expert word-smith. Our core problem is rather that of a schismatic soul. We have an exegesis to assist evaluation of creative work, to mediate between art and judge; but this explanatory text is never structurally neutral but neurotically oscillates between impulses to autoconnoisseurship and history. And because of its dubious grounding, you may notice as a reader that the exegesis all too frequently produces autoconnoisseurship of an egotistical kind and history of a bland kind. Neither is inherently critical; and neither conspicuously advances knowledge. In many ways, I feel, the problem of defining the research for the candidate is the problem of defining the exegesis.

At Monash University, we felt that the cliché defining doctoral research as 'a contribution to knowledge' was misleading and perhaps even pretentious in our disciplines. We appealed to a kind of truth to the calling. The objective in doctoral projects, we pleaded, was 'a cultural contribution of substantial significance'. This has been a very liberating declaration, which Monash as a whole received with relief and embraced warmly in amendments to the doctoral regulations. Our researchers are thus under no obligation to define their work in epistemological terms. They do not have to demonstrate a stride taken in global knowledge. But it creates other expectations and stresses on the exegesis. The work (or conceptual background) has to live on the page. It has to come to life again in order to appear as a significant cultural contribution and hence the writing cannot disappoint the high charter of the creative work. The creative material is in constant rebirthing through the text that sits beside it.

The issue of what work the exegesis should do may never be solved by reference to abstract definitions of research or creative arts, no matter how well steeped in the authority of other disciplines. This would be an approach of the Mandarins, for in referencing innumerable venerable academic virtues, 
it could well fail to reference experience. We now sit atop a considerable little mound of doctoral submissions-some brilliant, some premature, some overworked and some dire-upon which analysis can begin; and this observational argument is much likelier to yield helpful insights into the construction of exegetical essays than a whole phalanx of a priori ingredients for high rigour. Rather than a supplier-driven approach, a reader-oriented approach is called for.

Another key motif recommends this approach. Method in our field is not universally generalizable. The most interesting elements that you might forcefully promote to one researcher you would never whisper to another, for it would manifestly not apply; it could corrupt the intention or mess up the natural flow that the individual project indicates. Method in our area is best handled on a case-by-case basis; there is nothing paralleling scientific method. Each candidate establishes a method proper to himself or herself; and the applicability of any given discourse to candidates can only be seen on an individual basis. To formulate a method, and hence an exegetical framework, would risk dragooning the candidate into unworkable disciplines. As with negative theology (in which the pious scholar can tell you what God is not but would never presume to tell you what he or she is) (1) it seems prudent to emphasize what to avoid rather than what to include.

For these reasons, it has occurred to me that the most useful appreciation of what an exegetical essay should achieve may arise out of avoiding the numerous methodological pitfalls that litter the field. In this paper, therefore, I wanted to enumerate some of what I consider 'the sins' of exegetical writing; for I find that consideration of these 'sins' yields systematic insights into the structure of the task. There is a difference with the faults and omissions that might crop up in other fields, which might be characterized as errors (sfalmata); for the peculiar wrongheadedness that I want to identify is a fault (hamartia) of a kind that became theologically burdened, in later Hellenistic times, with implications of guilt. The list that I want to cover comprises indulgence, blandness, inconsequentiality, evasion, pretence, naivety, inconsistency, problematic ideology, poor structure, uncritical writing, the unpoetic and pomposity. I would like to devote the rest of this paper to treating each with a paragraph.

In all these shortcomings that I want to discuss, however, the one that I would not include is that the text fails to explain the work. I do not see it as at all obligatory to furnish a key to the meaning of the creative work; and this requirement should not be considered part of the rigour. Further, though in general each and every sin is equally wrong, none is unpardonable; and at any moment we may allow ourselves to be seduced, for a peculiar charm in the work may sustain a degree of presumption in the exegetical commentary. Numerous caveats of absolution must be described alongside each description of $\sin$.

\section{Indulgence}

The issue with indulgence is not about having fun. Artists are allowed to enjoy themselves and to project this relish in all candour. To disguise this element of pleasure would falsify the artistic project. Rather, indulgence in this context may be defined as the wanton concentration on material flattering to the abilities of the writer. We detect in the concept an element of selfgratification, an exhibitionist delivery or unnecessary rehearsing of esoteric knowledge. The reader is somewhat alienated because not included, not spoken to, not seduced. No attempt seems to have been made to negotiate with the reader's patience. But sometimes an author deserves to be indulged. It is a justified obsession in the context of the creative work. And whereas 
bellettrism, dilettantism and amateurship are anathema in other parts of the academic world, they are defensible expressions of enthusiasm in ours, for they may reveal essential aspects of the inspirational integrity of the artist's vision.

\section{Blandness}

There are two kinds of blandness. One is saying things that are neither here nor there, that are non-committal, lacking opinion or character. The other is saying things that do not require a proof, that do not invite contestation. The material collected is already well-enough known not to be brought together again, unless for the purpose of debate; but then the blandness would arise in the debate not being invoked or adequately pursued. Under blandness, you could mention the air of the platitude, the predictable thought, the kind that makes you suspect that other souls would have said the same thing, even though you cannot prove it. And even when you feel that others may not have said it, the utterance still strikes you as mediocre. The bland exegesis often cruels the hope of the creative work to reach cultural significance. It is often a hum-drum historical narration, for example, that buries the creative impulse.

\section{Inconsequentiality}

Material brought together without due connexions is inconsequential.(2) For example, a fact-worthy in its own right-may not be chased by an insight or a further fact which would support it. No matter how weighty the fact may be in another context, it is inconsequential here, for it is not argumentatively related to a meaningful structure. It is not given a constructive home. Hence, meaning is somewhat missing, as meaning lives in the synapses. As the etymology suggests, things do not follow one another to build up a case or a vision; therefore a case does not follow. It would be unfair to demand that everything said must be automatically yoked to an argument. Evocation and imaginative thoughts may be limited by this discipline. Writing can be flashy, learned, flitting and up to a point skittish. However, a point must be made, even if eccentrically conveyed.

\section{Evasion}

Writers of exegetical documents are often evasive; and the due that they most usually evade is talking about the creative work. Somehow, the aesthetic premises of the work are avoided. The text talks about matters on which there is no question regarding the artistic rightness of judgements. Judgements have assuredly been made on aesthetic or moral bases; but these artistic choices are not illuminated. Thus, the paradigm of the creative work is somewhat absent from the exegesis. The reader not inducted into the choices-and hence the method-of the artist. In this way, the criteria are not helpfully laid out.

\section{Pretence}

It is tempting to present the creative project as if it were absolutely defensible, as if a thorough investigation has been conducted, of which the creative work is the infallible outcome. Whom does one want to fool in projecting this fantasy? We sometimes find a dependence on social science to be erroneous or misleading. Partly this is because the creative force underlying an artistic undertaking is wayward and hardly foreseeable in scientific results. Pretension can also arise through the 'application' of theory, especially when the theory is of limited relevance but is artificially used for rhetorical purposes (as opposed to the garnishing or decorative or authoritative purposes which still fall on the side of the scholarly). The will to subsume the prestige of inappropriate discourses or texts tangential to the direction of the creative work is pretentious. 


\section{Naivety}

Alas, the opposite is just as scandalous. References may be partial and pitched eccentrically; but they cannot ignore with impunity all critical literature, or at least they cannot ignore the sense of it. The author has to be able to portray contemporary feeling at the sharp end. Failure to note creative work or critical writing which would contest (or even support the thesis) is disappointing for the reader, who wants to feel that the research has unearthed such key cultural connexions. Certain assumptions underlying the creative work (and its exegesis) could involve falsehood, disprovable by, or at least debatable according to, social science method. A failure to take into account revision in the terms of the discourse in recent times weakens the authority of the writer. It is not necessarily Romantic either, as is often the hope with 'purely intuitive' artistic conceits.

\section{Inconsistency}

I would typically identify inconsistency as a gap between the exegesis and the creative work; for it sometimes appears that they are possessed of a different spirit, perhaps because they were created at different times and under different pressures. This also arises within exegesis itself, as variations of discourse and voice can be quite disorienting. The logic and assumptions can be at variance with one another, not just the spiritual content, so to speak, which you would normally expect might reflect the unique vision of the individual. This therefore creates the impression of a lack of integrity, a single guiding mind that has brought both the creative work and its commentary into existence. Internal contradictions can be countenanced, of course, and are probably necessary up to a point; but these contradictions need to be expressed as poetic paradoxes and are somehow different from the fragmentation of writing that does not correspond to the broader vision.

\section{Problematic ideology}

In art, it would be ideal (in the utopian sense) for ideology to be immaterial, since inclusiveness would ban no discourse and frown upon no voice, irrespective of the opinion it carries. Everyone has a right to his or her own prejudice; and you have to allow that not all great art arises out of an open mind. Unfortunately, however, ideological soundness still comes into play, for the underlying cultural assumptions in an artistic project may be repugnant, as when the material is racist, sexist or snobbish. This chauvinism presents an insoluble problem for the examiner, who is required to give an honest response to form and content. He or she is sometimes put to the point in deciding which is more important and whether or not an element of odious content can be overlooked in favour of the gorgeous form. But then the unhelpful attitudes may also be revealed in the voice, the texture of both the exegetical writing and the creative work. You may suspect that there may be inappropriate metaphors, dubious analogies, all of which suggest an aesthetic miasma of contemptible moral origins, a fault that folds into bad taste. It could be said that style has always been understood as the reflection of an ethos. And so, much against our instincts, the natural faith in the moral - and aesthetic - calibre of the candidate is called into question. The confidence of the examiner is spooked by the ghost of fundamental wrongness. This crisis may never have arisen were it not for the exegesis; and I think that we have to be grateful that the issue has come to light.

\section{Poor structure}

Good structure depends on the judicious balance and flow between (a) the historical content, by implication the lineage of the artist or his or her creative work, (b) the placement of the creative work among contemporaries, (c) the contemporary critique of both and (d) the comment on the methods in creative work. These parts are apt to be either repetitious (when the core ideas 
are driven through each section) or incoherent (when the same ideas are detached from one another). In this, the mechanical function of the introduction and conclusion is vital for explaining the links and rhythms of the text and perhaps excusing the inevitable overlap in the several parts.

\section{The uncritical}

The presence of a scholarly apparatus is sometimes only understood as a necessary sacramental convention of academic writing, a tactical or diplomatic requirement to do learned obeisance. Its prime purpose, however, is not to show reverence but to separate and identify ideas that otherwise flow and coalesce in the body of the text. In turn, the purpose of identifying the various origins of the ideas - rather than letting them merge in glorious rhapsody - is to indicate the relative originality of the various contributions that go toward the current text. There is a critical disposition to this labour, which is sometimes little understood.

The critical is a faculty that requires a more sustained analysis. In essence, however, the uncritical means lacking curiosity for the criteria of judgement. It could mean a failure to see that the favourite themes or tropes of the research or text could be at issue, could be seen as conceits or otherwise thin or plain old platitudes. When authors are cited, the uncritical could mean a failure to see associations and values embedded in style, genre, imagery; it could be a failure to observe the bias or the tendentious character of cited texts. The inevitable result of uncritical writing is a boring and unstimulating outcome.

\section{The unpoetic}

The greatest stress arises with the expectation of imaginative freedom. The exegesis must rise - somewhat - to the poetic character of the creative work. It is a daunting prospect. It is a shame if the author excessively falls back upon social history or history of technology, or some other worthy area of knowledge, without interpretative inflexions. The agency of imagination must emerge in the linking of ideas. It is not easy to attempt a definition of the poetic; but the prosaic is easily identified, the hum-drum, the unimaginative, the literal, the grind of heavy data - base against mediocre or unoriginal insights. The poetic is recognized in the humour or levels of meaning in an art work, the understanding for images or spaces to embody concepts or make general reflections beyond their material and images. So too in the writing, either on the works or on the conditions that the works describe. This is revealed in the comparison and flow of ideas, verbal images, wit, paradox, the great range of qualities that make for engagement with the reader. The peculiar imaginative vivacity is also in language, probably spiked with metaphor, perhaps allusions, comparisons, liberties in summing up scholarship, and clever means of bracketing ideas. Ideally the exegesis explores scope for emotional content within the academic.

\section{Pomposity}

As in conversation, so in exegeses, pomposity is hard to suffer. It is the expression of arrogance and presumption. This could be as minor as reading one's own work as if one were a critic (as if ghost-writing one's own review). It could also arise with the presumption that one can explain the creative work, thus implicitly denying the viewer's independent interpretation or devaluing the spectator's own journey of discovery, a discourtesy at the least but at worst a negation of the work in favour of its creator. Pomposity can be seen when authors align their creative work with the loftiest in the western canon - with a qualitative implication - as if they are next in the line of accession to the archive. Pomposity may also be evident through mystifying the reader with oblique meanings (where not inherently fugitive) or artificial 
connexions. It may also be felt in statements implying: 'I don't need to explain', which lacks modesty as much as 'I can exhaustively explain the content of the works'. It is also off-putting and pompous when a reader assumes the reader's interest and sympathy, as if the author is already a cultural hero.

It is possible, in conclusion, to aver that some positive features should be present in an exegetical commentary. It is all too easy to extol antonyms for all of the sins above and call for clarity, vivacity, imagination, insight, perceptiveness, great knowledge, originality and the rest. Why not? These features, when found, nearly always accompany creative work of the most inspired kind. They are hard to bundle into one document; but the symmetry of creative work and exegetical text is a hard task-master. The exegesis must reflect the same qualities that are present in the creative work to effect the rehearsal and rebirthing that was suggested above. In truth, it is not an easy labour; but it is rewarding for candidate and reader alike; and the great consolation for all the pains is that neither the student nor the examiner needs to explain the ultimate meaning of the creative work.

\title{
Notes
}

1. Unless you speak in positive platitudes, such as God is truth, beauty, wisdom, light and so on, every virtue in which there is no contestation. Return to paper.

2. $c f$ Latin expression for finding fault in argumentative link: non sequitur. Return to paper.

Associate Professor Robert Nelson is Associate Dean, Research and Graduate Studies in the Faculty of Art and Design at Monash University. He has a PhD from LaTrobe Uiversity in Melbourne. He has consistently exhibited in both group and solo exhibitions in Melbourne and regional Victoria. He has published widely in journals, catalogues and anthologies, including Art Monthly Australia, Craft Victoria, Artlink and others. He has published feature articles and criticism in The Age and poetry in various magazines and catalogues.

\author{
TEXT Special Issue \\ No 3 April 2004 \\ http://www.griffith.edu.au/school/art/text/ \\ Editors: Julie Fletcher \& Allan Mann \\ General Editors: Nigel Krauth \& Tess Brady \\ Text@griffith.edu.au
}

